\title{
A Nonlinear Control Model of Growth, Risk and Structural Change
}

\author{
P. E. Petrakis, S. Kotsios \\ National and Kapodistrian University of Athens, Athens, Greece \\ Email:ppetrak@cc.uoa.gr,skotsios@di.uoa.gr
}

\begin{abstract}
Uncertainty is perceived as the means of removing the obstacles to growth through the activation of Knightian entrepreneurship. A dynamic stochastic model of continuous-time growth is proposed and empirically tested, including equilibrating and creative entrepreneurial activity. We find that uncertainty affects economic growth and the rate of return, and causes structural changes in portfolio shares for the two types of entrepreneurial events. Structural change depends mainly on the intertemporal rate of substitution, productivity ratios, and finally intersectoral difference in return and risk.
\end{abstract}

Keywords: Growth, Risk, Entrepreneurship, Structural Change

\section{Introduction}

This paper examines the relationship between growth and risk through structural change. Structural change is analyzed through the examination of growth, since it relates to entrepreneurship and uncertainty. Uncertainty is treated as the means of removing barriers to growth through the activation of Knightian entrepreneurship.

We assume that growth is the result of equilibrating and creative entrepreneurial events. Equilibrating entrepreneurial events (adaptive behaviour) are the most common ones and bring demand and supply to an equilibrium [1]. On the other hand, creative entrepreneurial events (innovative Schumpeterian behaviour) are those that result from the creation of new (innovative) products and services.

Considering structural change issues prompts discussion of "why industries grow at different rates and which industries come to have an increasing weight in the total output while others decline and eventually wane' [2]. In search for an answer, researchers usually bring up differences in income elasticities of domestic demand, supplyside productivity differences, or different productivity growth rates, which is the result of selection mechanisms within the general evolutionary process [2-10]. Changes in the relationship between intersectoral conditions of risk and return are believed to have implications for structural changes and economic growth. Thus, risk and uncertainty are examined in the framework of structural change and economic growth. Intuitively one can expect to find a causal relationship between uncertainty and structural change. However, this has not yet been verified using a growth structural change model.

A dynamic stochastic model of continuous-time growth is proposed, including two basic types of entrepreneurial events, based on the work of Turnovsky [11]. It includes three distinct 'crucial' individual concepts: growth rates, portfolio shares, and rates of return. Thus, our analysis includes the performance indexes (growth rates), 'incentives' (rates of returns) and 'results' (portfolio shares) of entrepreneurial behaviour. This paper therefore contributes to the analysis of uncertainty, entrepreneurship, and risk. It also contributes to the analysis of structural change patterns with regards to risk.

The rest of the paper is organized as follows. In Section 2 of the paper the sustainable growth conditions are discussed. Section 3 provides a short literature review on structural change. In Section 4 we introduce the model and its implications. Section 6 concludes.

\section{Sustainable Growth and Uncertainty}

The purpose of this study is to establish a theoretically acceptable relationship between growth and uncertainty taking into consideration the role of entrepreneurship. The argument runs as follows: uncertainty activates entrepreneurship, which stimulates social capital and influences growth. Thus, the focus is on the relationship between growth, entrepreneurship, and uncertainty. Social capital is the common ground where entrepreneurship and uncertainty operate. Do the above dynamics work towards the elimination of obstacles to sustainable growth? 
Lucas [12] rearranges the neoclassical model and establishes that our attention should be on human capital and its externalities on labour (L). Romer [13,14] augments this theory, arguing that additional investment in research could result in increasing returns through knowledge spillover embodied in human capital. What is important here is alertness ([15], i.e. the 'know- ledge' of where to find market data [16]). The process of finding entrepreneurial opportunities relates to the stock of knowledge (social capital) inherent in everyday life experience [17].

Yu [17], utilising a) Kirzner's [14] theory of entrepreneurial discovery, b) Schumpeter's [18] two types of economic responses (extraordinary and adaptive), and c) the Austrian theory of institutions as building blocks, constructs an entrepreneurial theory of institutional change and social capital accumulation. Yu [17,19], as well as other researchers in the field, do not use the concept of social capital as an alternative for institutions. However, social capital as defined by Westlund and Bolton [20] is greatly comparable to the concept of institutions, as described in $\mathrm{Yu}[17,19]$. The process of institutional change is the continuous interaction between entrepreneurial exploitation and exploitation of opportunities [21]. Institutions (stores of knowledge) emerge as a consequence of the attempt to reduce structural (as opposed to neoclassical static) uncertainty. Therefore, entrepreneurship expands institutional development and social capital accumulation. Evidently in this process there are secondround effects. Social capital accumulation boosts entrepreneurship through externalities. These externalities promote the distribution of information and generate asymmetric information. At the same time, institutions reinforce entrepreneurial alertness and the process of discovering new entrepreneurial opportunities [19]. Thus, entrepreneurship increases social capital. Thus entrepreneurship affects growth positively through social capital accumulation.

According to Brouwer [22], in Knight's [23] view, true uncertainty is the only source of profits because they vanish as soon as change becomes predictable, or they become costs if uncertainty is hedged. Brouwer [22] shows that diminishing returns to investment in innovation can be avoided with the use of Knightian uncertainty. This can be achieved through R\&D cooperation; that is, by creating social capital through R\&D networks. We can therefore suggest that uncertainty makes perpetual innovation more likely. Thus, growth and uncertainty are positively related. Knight [23] supports that rates of return on entrepreneurial investment vary around an average, and it is the relative entrepreneurial ability that is rewarded.

Entrepreneurs also create a great deal of uncertainty through Schumpeterian innovation, which creates confusion in the market. A lack of entrepreneurship indicates an over-reliance on old structures, interpretations, and understandings [17]. Thus, entrepreneurial activation is positively related with uncertainty.
From the above analysis, we can conclude that entrepreneurship and uncertainty are related, with the latter positively affecting entrepreneurship. Therefore, growth and uncertainty are related, with the latter positively affecting growth.

Montobbio [2], in his critical and concentrated literature review, presents three main trends stemming from studies on structural change:

a) Endogenous growth models assess the determinants of aggregate growth in a multi-sectoral economy $[14,24]$ but they incur difficulties in explaining major processes of structural change.

b) Industry life-cycle models examine growth, maturity and decline [25] but do not address 1) demand pressures and 2) the relationship between growth and sector that decline.

c) The supply and demand side factors approach seems to attract most of the recent work done in the field.

The supply side was first proposed by Schumpeter [18]. Kuznets [6] also stressed the importance of different impact of 1) technological innovations and 2) a selection mechanism based on competitive advantage. Pasinetti $[9,10]$ demonstrates that growth rates depend on productivity rates. Montobbio [2] shows aggregate productivity growth can be achieved without technological change at the firm level.

This paper follows the supply and demand side factors approach to structural change. The model includes basic characteristics of the supply side, especially the influence of uncertainty, productivity, and social capital and networks on the portfolio shares. In addition, in takes into account the intertemporal elasticity of substitution. It evidently shows how growth and structural change can be achieved simultaneously, without the use of further assumptions.

\section{The Model of Growth, Creative Equilibrating Events and the Role of Uncertainty}

The preceding analysis sets the basis for the introduction of a representative agent model based on three fundamental concepts: economic growth, and the two types of entrepreneurial events, including their basic characteristics. Obviously, this points to a stochastic growth model, which will include stochastic capital accumulation, capital return specification, and consumer utility maximisation procedures. The model is based on Turnovsky's [11] stochastic growth model with an entrepreneurial event.

We consider an economy, where the household and production sectors are consolidated. The representative agent consumes output over the period $(t, t+d t)$ at a non-stochastic rate $C d t$.

The agent distributes his resources between the two types of entrepreneurial events. This means that he func- 
tions within an environment of perfect information, with no costs or limitations regarding the initiation of a creative or equilibrating event.

The two types of entrepreneurial events influence growth rates in different ways. In particular:

a) The role of creative vs. equilibrating events, with regards to the accumulated flow of output over the period $(t, t+d t)$, is rather different (see description of Equation

(3) below).

b) The two types of entrepreneurial activities face different technologies. Each activity adds to the total production flow in the same way.

Each agent maximizes expected lifetime utility captured by a standard concave utility function:

$$
E_{0} \int_{0}^{\infty} U(C) e^{-b t} d t \text { with } U^{\prime}(C)>0 \text { and } U^{\prime \prime}(C)<0
$$

subject to the stochastic accumulation equation,

$$
d K^{c}+d K^{e}=d Y-C d t
$$

where:

$K^{c}=$ stock of physical capital devoted to creative entrepreneurial events at time $t$;

$K^{e}=$ stock of physical capital devoted to equilibrating events at time $t$;

$d Y=$ flow of output (from both entrepreneurial events) over the period $(t, t+d t)$.

The initial stocks of capital are given by $K_{0}^{c}$ and $K_{0}^{e}$.

\section{The Mechanics of Growth, Risk an Structural Change}

This section outlines the model. Subsection 4.1 gives the model's assumptions; 4.2 is concerned with the stochastic process; 4.3 analyzes the determinants of risk; 4.4 summarizes the findings concerned with the growth process; last, 4.5 examines the portfolio shares and the rates of return. Finally, Table 1 presents the findings of our theoretical analysis.

\subsection{The Model's Assumptions}

Besides the basic assumptions, which are:

a) Linearity in production equations;

b) Individuals are risk averse, which implies that $\gamma-1<0$, i.e. relatively large elasticity of intertemporal substitution.

The model adopts the following two additional hypotheses: c) $r_{c}>r_{e}$; i.e. the rate of return on creative entrepreneurial events is larger than that of equilibrating events;

d) $\sigma_{e}^{2}>\sigma_{c e}$, and $\sigma_{c}^{2}>\sigma_{c e}$; the risk of equilibrating and creative entrepreneurial events is greater than the covariance of risk between the two types of events. This hypothesis is based on the fundamental principle of portfolio structuring according to which the risk of each portfolio component is greater than the total portfolio risk. In other words, since the agent is risk averse, it always makes sense to reduce risk by composing portfolios that include both types of entrepreneurial events.

e) We assume that the production functions are linear in their components; that is, that $Y_{e}=\theta_{e} K^{e}$ and $Y_{c}=\theta_{c} K^{c}$, where $\theta_{e}, \theta_{c}$ the TFP variables in the two production technologies respectively. There is no a priori reason to assume that $\theta_{e} \neq \theta_{c}$; thus the model does not necessarily assume heterogeneity of the sectors (firms) in terms of productivity. However, for simplicity reasons the two productivities are different in notation. The consequences of identical intersectoral productivity values will be examined later.

Output is assumed to be generated from capital through the following stochastic process:

$$
\begin{aligned}
& d Y(t)=F\left(K^{e}\right) d t+F\left(K^{c}\right) d t \\
& +H\left(K^{e}\right) d y^{e}+H\left(K^{c}\right) d y^{c}
\end{aligned}
$$

Equation (3) has the following interpretation: the change in total output depends on deterministic events and stochastic episodes stemming from equilibrating and creative entrepreneurial activity. $F\left(K^{c}\right)+F\left(K^{e}\right)$ represent the deterministic effects of creative and equilibrating events respectively, whereas $H\left(K^{e}\right) d y^{e}+H\left(K^{c}\right) d y^{c}$ represent the stochastic events in each category of entrepreneurship.

The stochastic terms in the production function are based on two crucial assumptions: 1) $H\left(K^{i}\right), i=e, c$ is constant and the shocks enter the production function additively, 2) or $H\left(K^{i}\right)=h K^{i}, i=e, c$ where the disturbances are proportional to the aggregate capital stock, thus entering the production function in a multiplicative way. The assumptions regarding the stochastic disturbance terms are crucial for obtaining tractable, closedform solutions to the optimisation problem.

Stochastic disturbances of creative events are additive to the model. Equilibrating events, however, enter the model in a multiplicative function. Thus, according to this specification, equilibrating events are assumed to depend on the existing level of capital, whereas creative events are independent of the stock of capital.

Total capital stock held by the representative agent is 
denoted in the following way:

$$
K \equiv K^{e}+K^{c} \equiv W
$$

with the corresponding portfolio shares being

$$
n_{e} \equiv \frac{K^{e}}{W}, n_{c}=1-n_{e} \equiv \frac{K^{c}}{W}
$$

From relationship (5) we see that

$$
K^{e}=n_{e} K, \quad K^{c}=n_{c} K, \quad n_{e}+n_{c}=1,
$$

where $n_{e}, n_{c}$ are the corresponding portfolio shares.

\subsection{The Stochastic Processes}

Capital (K) follows a continuous time stochastic process:

$$
d K=\psi K d t+K d k, \quad \psi \in \mathfrak{R}
$$

where $\psi=\frac{F(K)}{K}-\frac{C}{K}$ is the growth rate of capital and $d k$ denotes a stochastic component. The properties of this stochastic component are: $E(d k)=0$ and $\operatorname{Var}(d k)=\sigma_{K}^{2} d t, \sigma_{K}^{2}=\frac{H^{2}}{K^{2}} \sigma_{y}^{2}$

- The rate of return on capital occupied in equilibrating entrepreneurship is determined through the following stochastic process:

$$
d R_{e}=r_{e} d t+d u_{e}
$$

The variance of the stochastic part of (7) is given by $\operatorname{Var}\left(d u_{e}\right)=\sigma_{e}^{2} d t$

Stochastic real rate of return on capital occupied in creative events is described through a similar stochastic process:

$$
d R_{c}=r_{c} d t+d u_{c}
$$

With the variance of the stochastic part being equal to $\operatorname{Var}\left(d u_{c}\right)=\sigma_{c}^{2} d t$.

The deterministic parts $r_{e} d t$ and $r_{c} d t$ denote the rates of return on the two types of capital. The stochastic parts are normally distributed with $E(d u)=0$ and $\operatorname{Var}(d u)=\sigma_{u}^{2} d t$. They represent the risks that the agent undertakes when he employs capital on equilibrating and creative entrepreneurship.

\subsection{The Determinants of Risk}

Theorem 4.3.1: The following relations hold:

$$
\sigma_{e}^{2}=\theta_{e}^{2} \sigma_{K}^{2}, \quad \sigma_{c}^{2}=\theta_{c}^{2} \sigma_{K}^{2}
$$

(Proof available upon request)
Theorem 4.3.1 suggests that the two levels of risk associated with entrepreneurial equilibrating and creative events are directly dependent upon the corresponding productivity ratio. They are also directly related to the stochastic part of capital accumulation, described by the variance. This is consistent with economic intuition since it implies that economies with small capital accumulation variance (i.e. low density business cycles) are characterized by low levels of entrepreneurial risk. The positive relationship between entrepreneurial risk and productivity is also an anticipated outcome since according to theorem 4.3.1 entrepreneurial risk, and thus the rate of return, has a positive relationship with productivity.

\subsection{The Growth Process}

The functional form portraying the relationship between individual entrepreneurial risk and the growth rate of capital, establishes the mechanism and the necessary conditions through which the two types of risk influence the rate of growth in our model. In order to address these two issues we introduce the following optimisation problem:

$$
\max _{C} E_{0} \int_{0}^{+\infty} \frac{1}{\gamma} C^{\gamma} e^{-b t} d t
$$

s.t.

$$
d K=\psi K d t+\rho K d z
$$

In other words, we want to maximise the expected value of the following utility function

$$
U(C)=\frac{1}{\gamma} C^{\lambda} e^{-b t},-\infty<\gamma<1
$$

where $C$ is the agent's consumption and $b$ is the discount rate.

The following result plays an essential role in the study of the comparative statics.

Theorem 4.4.1: In equilibrium the following hold:

$$
\begin{gathered}
\frac{\partial \psi}{\partial \sigma_{e}^{2}}=-\frac{1}{2}\left(\frac{1}{\theta_{e}}\right)^{2}(\gamma-1), \\
\frac{\partial \psi}{\partial \sigma_{c}^{2}}=-\frac{1}{2}\left(\frac{1}{\theta_{c}}\right)^{2}(\gamma-1)
\end{gathered}
$$

\section{(Proof available upon request)}

The effect of entrepreneurial risk on growth depends on the intertemporal elasticity of substitution. When large (i.e. $\gamma<1$ ) the effect of risk on growth is positive. When $\gamma>1$ then the effect is negative. This effect also depends on the reciprocal of productivity ratio, where the larger 
the productivity the smaller its influence on growth. This fact is demonstrated in the following theorem:

Theorem 4.4.2: The following inequalities are valid:

$$
\frac{\partial \psi}{\partial \sigma_{e}^{2}}>0, \frac{\partial \psi}{\partial \sigma_{c}^{2}}>0
$$

Moreover, in both cases, entrepreneurial risk has a direct relationship with the aggregate capital stock and an inverse relationship with productivity. The greater the quantity of aggregate capital, the larger the influence of risk on growth. On the other hand, the larger the productivity in the economy, the weaker the influence of risk on growth. In other words the greater the average ratio in the economy, the greater is the risk influence, as the financial theory suggests. On the other hand, the larger the productivity in the economy is, the smaller the effect of risk on growth. Different sector productivity levels imply differences on their impact on growth. Thus, if $\theta_{e}>\theta_{c}$, that is the productivity ratio in the equilibrating sector is greater than the productivity ratio in the creative sector, then if risk increases (decreases) by the same amount in both sectors, the impact on growth will be smaller (larger) for the equilibrating events vs. the creative events.

\subsection{Portfolio Shares and Rates of Return of Entrepreneurial Events}

By using the stochastic accumulation equation we have successively shown:

$$
d K=d Y-C d t=d Y_{e}+d Y_{c}-C d t
$$

Dividing by $\mathrm{K}$ we get

$$
\begin{aligned}
& \frac{d K}{K}=\frac{d Y_{e}}{K}+\frac{d Y_{c}}{K}-\frac{C}{K} d t= \\
& =n_{e} \frac{d Y_{e}}{K^{e}}+n_{c} \frac{d Y_{c}}{K^{c}}-\frac{C}{K} d t=n_{e}\left(d R_{e}\right)+n_{c}\left(d R_{c}\right)-\frac{C}{K} d t= \\
& =r_{e} n_{e} d t+n_{e} d u_{e}+r_{c} n_{c} d t+n_{c} d u_{c}-\frac{C}{K} d t= \\
& =\left(r_{e} n_{e}+r_{c} n_{c}-\frac{C}{K}\right) d t+n_{e} d u_{e}+n_{c} d u_{c}=\left(r_{e} n_{e}+r_{c} n_{c}-\frac{C}{K}\right) d t+d k
\end{aligned}
$$

with, $n_{e}+n_{c}=1$. We can easily prove that the variance of this stochastic process satisfies the relation

$$
\sigma_{K}^{2}=n_{e}^{2} \sigma_{e}^{2}+n_{c}^{2} \sigma_{c}^{2}+2 n_{e} n_{c} \sigma_{c e}
$$

where $\sigma_{c e}$ is the covariance of $d R_{e}$ and $d R_{c}$.

This is a standard portfolio construction statement. As we have already seen above, the variances of equilibrating and creative events are connected with the covariance of the $\sigma_{c e}$ with the basic relation of $\sigma_{e}^{2}>\sigma_{c e}$ and $\sigma_{c}^{2}>\sigma_{c e}$

The original optimisation problem is transformed to

$$
\max _{\mathrm{C}, \mathrm{n}_{\mathrm{c}}, n_{\mathrm{e}}} E_{0} \int_{0}^{+\infty} \frac{1}{\gamma} C^{\gamma} e^{-b t} d t, \quad-\infty<\gamma<1
$$

s.t.

$$
\frac{d K}{K}=\left(r_{e} n_{e}+r_{c} n_{c}-\frac{C}{K}\right) d t+d k
$$

with

$$
\begin{gathered}
n_{e}+n_{c}=1 \\
\sigma_{K}^{2}=n_{e}^{2} \sigma_{e}^{2}+n_{c}^{2} \sigma_{c}^{2}+2 n_{e} n_{c} \sigma_{c e}
\end{gathered}
$$

Theorem 4.5.1: The first-order conditions for the optimisation problem can be written as follows

$$
\begin{gathered}
(\delta \gamma)^{1 /(\gamma-1)}=\frac{b-\left(r_{e} \hat{n}_{e}+r_{c} \hat{n}_{c}\right) \gamma-\frac{1}{2} \gamma(\gamma-1) \sigma_{K}^{2}}{1-\gamma} \\
\delta \gamma=\left(\frac{\widehat{C}}{K}\right)^{\gamma-1} \\
(\gamma-1)\left(\hat{n}_{c} \sigma_{c}^{2}+\hat{n}_{e} \sigma_{c e}\right)+r_{c}=\frac{\mu}{\delta \gamma K^{\gamma}} \\
(\gamma-1)\left(\hat{n}_{e} \sigma_{e}^{2}+\hat{n}_{c} \sigma_{c e}\right)+r_{e}=\frac{\mu}{\delta \gamma K^{\gamma}} \\
\hat{n}_{c}+\hat{n}_{e}=1
\end{gathered}
$$

where $\hat{n}_{e}, \hat{n}_{c}, \widehat{C}$ are the maximum achieved values of $n_{e}, n_{c}, C$, and $\mu$ is the Lagrange multiplier, related to the equation $n_{c}+n_{e}=1$.

\section{(Proof available upon request)}

These above equations describe the solution of our optimisation problem. For the sake of the appearances, in the next paragraphs we will omit the hat symbol. The reader should keep in mind that we refer to the optimal values. Let us now assume that the quantities $n_{e}, n_{c}, r_{e}, r_{c}$ are functions of $\sigma_{e}^{2}$. Differentiating the above equations, (proof on request), with respect to $\sigma_{e}^{2}$, we get:

$$
\begin{gathered}
\frac{\partial n_{e}}{\partial \sigma_{e}^{2}}=-\frac{(\gamma-1) n_{e}^{2}}{2\left(r_{c}-r_{e}\right)}, \\
\frac{\partial n_{c}}{\partial \sigma_{e}^{2}}=-\frac{(\gamma-1) n_{e}^{2}}{2\left(r_{c}-r_{e}\right)} \\
\frac{\partial r_{e}}{\partial \sigma_{e}^{2}}=-(\gamma-1) n_{e}+\frac{(\gamma-1)^{2} n_{e}^{2}\left(\sigma_{e}^{2}-\sigma_{c e}\right)}{2\left(r_{c}-r_{e}\right)} \\
\frac{\partial r_{c}}{\partial \sigma_{e}^{2}}=\frac{(\gamma-1)^{2} n_{e}^{2}\left(\sigma_{c e}-\sigma_{c}^{2}\right)}{2\left(r_{c}-r_{e}\right)}
\end{gathered}
$$


Accordingly for the special case where the quantities $n_{e}, n_{c}, r_{e}, r_{c}$ are considered as functions of the variable $\sigma_{c}^{2}$, we get:

$$
\begin{gathered}
\frac{\partial n_{e}}{\partial \sigma_{c}^{2}}=-\frac{(\gamma-1) n_{c}^{2}}{2\left(r_{c}-r_{e}\right)} \\
\frac{\partial n_{c}}{\partial \sigma_{c}^{2}}=-\frac{(\gamma-1) n_{c}^{2}}{2\left(r_{c}-r_{e}\right)} \\
\frac{\partial r_{e}}{\partial \sigma_{c}^{2}}=\frac{(\gamma-1)^{2} n_{c}^{2}\left(\sigma_{e}^{2}-\sigma_{c e}\right)}{2\left(r_{c}-r_{e}\right)} \\
\frac{\partial r_{c}}{\partial \sigma_{c}^{2}}=-(\gamma-1) n_{c}+\frac{(\gamma-1)^{2} n_{c}^{2}\left(\sigma_{c e}-\sigma_{c}^{2}\right)}{2\left(r_{c}-r_{e}\right)}
\end{gathered}
$$

From the comparative statics presented above we conclude that there are three variables that play a significant role: 1) the difference between the rates of return on the two entrepreneurial activities, which is reciprocal to the degree of structural change, 2) the intertemporal elasticity of substitution, which is directly related to structural change, and 3) the existing portfolio share, which has a strong impact because of the exponent. The larger the difference between the two rates of return (creative vs. equilibrating activities), the smaller the effect of structural change is expected to be. It is also noted that the larger the intertemporal rate of substitution, the larger the value of return $(\gamma-1)$ and thus, the larger the extent of structural change. Finally, the greater the portfolio share, the larger the effect of entrepreneurial risk on portfolio shares will be.

The involvement of portfolio share on structural change requires further elaboration. The influence of existing portfolio shares refers to the concept of network effects and social capital accumulation. The larger the portfolio shares, the greater the effects on entrepreneurial activity, the larger is the social capital employed in the production function, and the greater the influences on sectoral growth.

Regarding the impact of entrepreneurial risk on the rates of return, the analysis becomes more complicated. The factors mentioned above still play a significant role, as in the case of portfolio shares. In addition, there are two more terms which appear to affect this relationship. These are the difference $\sigma_{e}^{2}-\sigma_{c e}$ for the equilibrating events and the difference $\sigma_{c e}-\sigma_{c}^{2}$ for the creative events. In both cases, the central principle of portfolio construction holds. That is, the risk involved in equilibrating and creative entrepreneurial events is greater than the covariance between the two types of risk. The greater the magnitude of these differences the larger the degree to which risk affects the rates of return.
We are now ready to obtain our next results:

Theorem 4.5.2:

If $r_{c}>r_{e}$ then

$$
\begin{array}{ll}
\frac{\partial n_{e}}{\partial \sigma_{e}^{2}}>0, & \frac{\partial n_{c}}{\partial \sigma_{e}^{2}}<0 \\
\frac{\partial n_{e}}{\partial \sigma_{c}^{2}}>0, & \frac{\partial n_{c}}{\partial \sigma_{c}^{2}}<0
\end{array}
$$

Proof: Obvious from the above formulas and the fact that $\gamma-1<0$.

These results are particularly interesting regarding the impact of risk on portfolio shares in the two entrepreneurial activities. Due to the difference in the rates of return between creative and equilibrating events, the higher level of risk involved in creative events directs total entrepreneurial activity more towards equilibrating activities than creative ones. The opposite also holds. So the level of risk essentially determines the nature of the entrepreneurial activity adopted (creative-equilibrating). In the case where both types of risk are in high levels, one should expect equilibrating entrepreneurship to dominate creative entrepreneurship. This fact will also have a positive effect on economic growth. This result influences the intertemporal elasticity of substitution, making agents more willing to give up consumption stemming from the equilibrating sector rather than the creative sector. As a matter of fact, the two conditions, $r_{c}>r_{e}$ and $\gamma<1$, should coincide if the particular type of structural change takes place. If one of the above two relationships changes direction, then one condition could offset the other. Thus, for a steady-state situation, the larger the reward of creative entrepreneurship the less the required intertemporal elasticity of substitution.

Finally, we test the relationship between entrepreneurial risk and the economy's growth rate, without distinguishing between the two types of entrepreneurship. In essence, we accept that

Theorem 4.5.3: If $r_{c}>r_{e}$ and $\sigma_{e}^{2}>\sigma_{c e}, \sigma_{c}^{2}>\sigma_{c e}$ then:

$$
\frac{\partial r_{e}}{\partial \sigma_{e}^{2}}>0, \quad \frac{\partial r_{c}}{\partial \sigma_{e}^{2}}<0
$$

Proof: Obvious from the above formulas and the fact that $\gamma-1<0$.

Theorem 4.5.4: If $r_{c}>r_{e}$ and $\sigma_{e}^{2}>\sigma_{c e}, \sigma_{c}^{2}>\sigma_{c e}$

then:

$$
\frac{\partial r_{e}}{\partial \sigma_{c}^{2}}>0, \quad \frac{\partial r_{c}}{\partial \sigma_{c}^{2}} ? 0
$$

Proof: Obviously by the above formulas and the fact that $\gamma-1<0$. 
Theorem 4.5.5: If $\gamma<1$ we have at the equilibrium:

$$
\frac{\partial \psi}{\partial \sigma_{K}^{2}}>0
$$

Proof: Indeed, from equation (37) we have:

$$
\begin{aligned}
& \frac{1}{\gamma} C^{\gamma}-b \delta K^{\gamma}+\psi K \delta \gamma K^{\gamma-1}+ \\
& \frac{1}{2} \sigma_{K}^{2} K^{2} \delta \gamma(\gamma-1) K^{\gamma-2}=0
\end{aligned}
$$

which means that

$$
\frac{\partial \psi}{\partial \sigma_{K}^{2}}=-\frac{1}{2}(\gamma-1)>0
$$

Thus it is proved that risk and growth are positively related.

Table 1 presents the findings from the preceding analysis. We concentrate on the results regarding the effect of both types of entrepreneurial events on growth rate, portfolio shares, and rates of return.

a) The effect of a change in equilibrate risk

In equilibrating events, risk has a positive relationship with the corresponding rate of return. In turn, it has a negative relationship with the rate of return of the equilibrating events. In this case, the portfolio share of equilibrating entrepreneurial events will increase against the portfolio share of creative events and eventually the growth rate will increase. Otherwise, a decrease in equilibrating entrepreneurship risk, decreases the rate of return and the portfolio share of equilibrating events. The total growth rate in this case will fall.

b) The effect of a change in creative risk

An increase (decrease) in the risk of a creative entrepreneurial event will increase (decrease) the corresponding rate of return while having the opposite effect on the rate of return of an equilibrating event. However the increase (decrease) in the risk of a creative event will shrink the corresponding portfolio share and will increase (decrease) the portfolio share of equilibrating events. Eventually, the total rate of growth will increase (decrease). The above comments hold when the creative risk influences positively the rate of return of creative events.

c) How the portfolio share of creative entrepreneurial events could be increased

Evidently, any kind of increase in risk will increase the portfolio share of equilibrating events. Then the question arises regarding the conditions that need to hold in order for the portfolio share of creative events to increase. Two mutually exclusive conditions can provide the conditions for the creative portfolio share to be increased. The first is that the rate of return of creative events is less than the rate of return of equilibrating events. In other words, the creative sector expands when the risk becomes smaller than the level of the risk of equilibrating events. The second refers to the intertemporal elasticity of substitution. The lower its value, the larger the portfolios share of the creative events. This last result should be evaluated in the light of the fact that the model pinpoints the direction in the change of the basic variables as we depart from the equilibrium point and for very small changes. Thus, an increase in the high (by definition) risk of creative events reduces their portfolio share.

d) The question of possible uniformity of growth

Equations (24-25) and (26-31) imply that uniform growth can be achieved when the existing portfolios of the two entrepreneurial events are equal. Since this is a rare situation, we conclude that risk will exercise non-uniform influences on the different portfolio shares.

\section{Conclusions}

This paper explores the fundamental growth question regarding which forces and under what conditions the obstacles to sustainable growth can be removed. The answer focuses on the role of uncertainty. The outcome of the analysis underlines the fact that uncertainty affects growth and structural change. In turn, structural change impacts growth, if the agent follows the basic principles of portfolio construction.

\section{References}

[1] P. Petrakis, "Entrepreneurship and growth: Creative and equilibrating events," Small Business Economics, Vol. 9 No. 5, pp. 383-402, 1997.

[2] F. Montobbio, "An evolutionary model of industrial growth and structural change," Structural Change and Economic Dynamics, No.13, pp. 387-414, 2002.

[3] W. J. Baumol, "Macroeconomics of unbalanced growth: The anatomy of urban crisis," American Economic Review 57, pp. 415-426, 1967.

[4] W. J. Baumol, S. A. B. Blackman, and E. N. Wolff, "Unbalanced growth revisited: Asymptotic stagnancy and new evidence," American Economic Review, No. 75, pp. 806-817, 1985.

[5] S. Kuznets, "Economic growth and nations: Total output and production structure," Cambridge University Press, Cambridge, 1971.

[6] S. Kuznets., "Economic development, the family and income distribution. selected essays," Cambridge University Press, Cambridge, 1988.

[7] J. S. Metcalfe, "Evolutionary economics and creative destruction," Routledge, London, 1998.

[8] J. S. Metcalfe, "Restless capitalism: Increasing returns and growth in enterprise economics," Mimeo, CRIC, Manchester, March 1999.

[9] L. Passinetti, "Structural change and economic growth: A theoretical essay on the dynamics of the wealth of nations," 
Cambridge University Press, Cambridge, 1981.

[10] L. Passinetti, "Structural change and economic dynamics," Cambridge University Press, Cambridge, 1993.

[11] S. J. Turnovsky, "Methods of macroeconomic dynamics," MIT Press, Cambridge, 2000.

[12] R. J. Lucas, "On the mechanics of economic development," Journal of Monetary Economics, No. 22, pp. 3-42, January 1988.

[13] P. M. Romer, "Increasing returns and long-run growth," Journal of Political Economy, Vol. 94, No. 5, pp. 10021037, 1986.

[14] P. M. Romer, "Endogenous technological change," Journal of Political Economy, Vol. 98, No. 5, pp. S71-102, 1990.

[15] I. M. Kirzner, "Competition and Entrepreneurship," University of Chicago Press, Chicago, 1973.

[16] R. G. Holcombe, "Entrepreneurship and economic growth," Quarterly Journal of Austrian Economics, Vol. 1, No. 2, pp. 45-62, Summer 1998.

[17] T. F. L. Yu, "Entrepreneurial alertness and discovery" Review of Austrian Economics, Vol. 14, No. 1, pp. 47-63, 2001a.
[18] J. Schumpeter, "The instability of capitalism," The Economic Journal, No. 38, pp. 361-386, Vol. 123, No. 2, pp. 297-307, 1928.

[19] T. F. L. Yu, "An entrepreneurial perspective of institutional change," Constitutional Political Economy, Vol. 12, No. 3, pp. 217-236, 2001b.

[20] H. Westlund and R. Bolton, "Local social capital and entrepreneurship," Small Business Economics, No.21, pp. 77-113, 2003.

[21] G. Dosi and F. Malebra, "Organizational learning and institutional embeddedness. In: Organization and strategy in the evolution of the enterprise," Macmillan, London, pp. 1-24, 1996

[22] M. Brouwer, "Entrepreneurship and uncertainty: innovation and competition among many," Small Business Economics, Vol. 15, No. 2, pp. 149-160, 2000.

[23] F. H. Knight, "Risk, uncertainty and profit," Houghton Mifflin, New York, 1921.

[24] P. Aghion and P. Howitt, "Endogenous growth theory," MIT Press, Cambridge, 1998.

[25] D. Audretch, "An empirical test of the industry life cycle," Welwirtschaftliches Archiv,1987 


\section{Appendix A. Tables}

Table 1. Summary of theoretical findings the relation among growth, portfolio shares, rates of return, and risk of two types of entrepreneurial events.

\begin{tabular}{|c|c|c|c|c|}
\hline \multirow{2}{*}{$\alpha / \alpha$} & \multirow{2}{*}{ Theorems } & \multirow{2}{*}{ Variables } & \multicolumn{2}{|c|}{ Risk } \\
\cline { 4 - 5 } & & & $\sigma_{e}^{2}$ & $\sigma_{c}^{2}$ \\
\hline$(1)$ & 5.4 .2 & $\psi$ & $>0$ & $>0$ \\
\hline$(2)$ & 5.5 .2 & $n_{e}$ & $>0$ & $>0$ \\
\hline$(3)$ & 5.5 .2 & $n_{c}$ & $<0$ & $<0$ \\
\hline$(4)$ & $5.5 .3,5.5 .4$ & $r_{e}$ & $>0$ & $>0$ \\
\hline$(5)$ & $5.5 .3,5.5 .4$ & $r_{c}$ & $<0$ & $? 0$ \\
\hline$(6)$ & 5.5 .5 & \multicolumn{3}{|c}{$\frac{\partial \psi}{\partial \sigma_{K}^{2}}>0$} \\
\hline
\end{tabular}

\section{Appendix B. Proof of theorem 4.3.1 (for the reviewers only)}

We shall work with the first relation, $d K=d Y-C d t$. We suppose that $Y_{e}=\theta_{e} K^{e}, \theta_{e}$ a constant during the period $(t, t+d t)$ and thus $\theta_{e}$ is the productive ratio for the equilibrating events. This means that $Y_{e}=\theta_{e} n_{e} K$.

We know that $d R_{e}=\frac{d Y_{e}}{K^{e}}$. Using the Ito's Lemma and equation (6) we get:

$d Y_{e}=\theta_{e} n_{e} \psi K d t+\theta_{e} n_{e} K d k$ and thus

$$
\frac{d Y_{e}}{K^{e}}=\frac{d Y_{e}}{n_{e} K}=\theta_{e} \psi d t+\theta_{e} d k
$$

We know that $d R_{e}=\frac{d Y_{e}}{K^{e}}$ and thus by means of equation 7 we have: $\operatorname{Var}\left(d u_{e}\right)=\operatorname{Var}\left(\theta_{e} d k\right)$ or $\sigma_{e}^{2} d t=\theta_{e}^{2} \sigma_{K}^{2} d t$ which means that $\sigma_{e}^{2}=\theta_{e}^{2} \sigma_{K}^{2}$. Working similarly, we take the second equation, too.

\section{Appendix C. Proof of theorem 4.4.1 (for the reviewers only)}

We have to deal with the following problem:

$$
\max _{C} E_{0} \int_{0}^{+\infty} \frac{1}{\gamma} C^{\gamma} e^{-b t} d t, \quad-\infty<\gamma<1
$$

s.t.

$$
\frac{d K}{K}=\psi d t+d k
$$

This is a classical stochastic optimal control problem. We define $V(K, t)=\max _{C} E_{t} \int_{t}^{+\infty} \frac{1}{\gamma} C^{\gamma} e^{-b t} d t$. The corresponding expression to be maximised with respect to $C$ is

$$
e^{-b t} \frac{1}{\gamma} C^{\gamma}+\frac{\partial V}{\partial t}+\psi K \frac{\partial V}{\partial K}+\frac{1}{2} \sigma_{K}^{2} K^{2} \frac{\partial^{2} V}{\partial K^{2}}
$$

Assuming that the unknown function $V(K, t)$ has the separable form $V(K, t)=e^{-b t} X(K)$, Equation (43) becomes:

$$
\frac{1}{\gamma} C^{\gamma}-b X+\psi K X_{K}+\frac{1}{2} \sigma_{K}^{2} K^{2} X_{K K}
$$

The value of $C$ where the maximum is achieved, denoted by $\hat{C}$, must make (44) equal to zero. This is the well-known Bellman equation with $X(K)$ as the unknown function. In order to solve it, we postulate a solution of the form: $X(K)=\delta K^{\gamma}$. Substituting this solution for (44), we have:

$$
\frac{1}{\gamma} \widehat{C}^{\gamma}-b \delta K^{\gamma}+\hat{\psi} K \delta \gamma K^{\gamma-1}+\frac{1}{2} \sigma_{K}^{2} K^{2} \delta \gamma(\gamma-1) K^{\gamma-2}=0
$$

Substituting now for this equation the relation (9), we get

$$
\begin{aligned}
& \frac{1}{\gamma} \widehat{C}^{\gamma}-b \delta K^{\gamma}+\hat{\psi} K \delta \gamma K^{\gamma-1}+ \\
& \frac{1}{2}\left(\frac{K}{\theta_{e}}\right)^{2} \sigma_{e}^{2} \delta \gamma(\gamma-1) K^{\gamma-2}=0
\end{aligned}
$$

Finally, by differentiating (46), with respect to $\sigma_{e}^{2}$ and rewriting $\psi$ instead of $\hat{\psi}$ we get

$$
\frac{\partial \psi}{\partial \sigma_{e}^{2}} \delta \gamma K^{\gamma}+\frac{1}{2} \delta \gamma\left(\frac{1}{\theta_{e}}\right)^{2}(\gamma-1) K^{\gamma}=0
$$

which means that

$$
\frac{\partial \psi}{\partial \sigma_{e}^{2}}=-\frac{1}{2}\left(\frac{1}{\theta_{e}}\right)^{2}(\gamma-1)
$$

Similarly, we can prove that

$$
\frac{\partial \psi}{\partial \sigma_{c}^{2}}=-\frac{1}{2}\left(\frac{1}{\theta_{c}}\right)^{2}(\gamma-1)
$$

and the theorem has been established. 


\section{Appendix D. Proof of theorem 4.5.1 (for the} reviewers only)

We have to solve the following optimisation problem.

$$
\max _{C, n_{e}, n_{e}} E_{0} \int_{0}^{+\infty} \frac{1}{\gamma} C^{\gamma} e^{-b t} d t, \quad-\infty<\gamma<1
$$

s.t.

$$
\frac{d K}{K}=\left(r_{e} n_{e}+r_{c} n_{c}-\frac{C}{K}\right) d t+d k
$$

with

$$
\begin{gathered}
n_{e}+n_{c}=1 \\
\sigma_{K}^{2}=n_{e}^{2} \sigma_{e}^{2}+n_{c}^{2} \sigma_{c}^{2}+2 n_{e} n_{c} \sigma_{c e}
\end{gathered}
$$

This is a classical stochastic optimal control problem; to solve it we shall follow Turnovsky [11]. The corresponding Lagrangian expression to be maximised is:

$$
\begin{aligned}
& e^{-b t} \frac{1}{\gamma}+\frac{\partial V}{\partial t}+\left(r_{e} n_{e}+r_{c} n_{c}-\frac{C}{K}\right) K \frac{\partial V}{\partial K}+ \\
& \frac{1}{2} \sigma_{K}^{2} K^{2} \frac{\partial^{2} V}{\partial K^{2}}+\mu\left[1-n_{c}-n_{e}\right]
\end{aligned}
$$

We assume now that the unknown function $V(K, t)$, has the separable form $V(K, t)=e^{-b t} X(K)$, we substitute this value into (53) and we put then, the partial derivatives of the resulting expression, with respect to the variables $C, n_{e}, n_{c}, \mu$, equal to zero. We shall take:

$$
\begin{aligned}
C^{\gamma-1} & =X_{K} \\
r_{c} K X_{K}+\left(n_{c} \sigma_{c}^{2}+n_{e} \sigma_{c e}\right) K^{2} X_{K K}-\mu & =0 \\
r_{e} K X_{K}+\left(n_{e} \sigma_{e}^{2}+n_{c} \sigma_{c e}\right) K^{2} X_{K K}-\mu & =0 \\
n_{e}+n_{c} & =1
\end{aligned}
$$

These equations determine the optimal values: $\frac{C}{K}, n_{e}, n_{c}, \mu$ as functions of $X_{K}, X_{K K}$. Furthermore, substituting once more, the values we got above, for the relation (53) and cancelling the term $e^{-b t}$ we take the Bellman equation:

$$
\begin{aligned}
& \frac{1}{\gamma} \widehat{C}^{\gamma}-b X(K)+\left(r_{e} \widehat{n}_{e}+r_{c} \widehat{n}_{c}-\left(\frac{\widehat{C}}{K}\right)\right) K X_{K}+ \\
& \frac{1}{2} \sigma_{K}^{2} K^{2} X_{K K}=0
\end{aligned}
$$

where denotes optimised value. To solve the Bellman equation we postulate a solution of the form $X(K)=\delta K^{\gamma}$, where the coefficient $\delta$ can be determined. Substituting this into the Bellman equation and the equations (54), we perform some manipulations:

$$
\begin{gathered}
(\delta \gamma)^{1 /(\gamma-1)}=\frac{b-\left(r_{e} \hat{n}_{e}+r_{c} \hat{n}_{c}\right) \gamma-\frac{1}{2} \gamma(\gamma-1) \sigma_{K}^{2}}{1-\gamma} \\
\delta \gamma=\left(\frac{\widehat{C}}{K}\right)^{\gamma-1} \\
(\gamma-1)\left(\hat{n}_{c} \sigma_{c}^{2}+\widehat{n}_{e} \sigma_{c e}\right)+r_{c}=\frac{\mu}{\delta \gamma K^{\gamma}} \\
(\gamma-1)\left(\hat{n}_{e} \sigma_{e}^{2}+\hat{n}_{c} \sigma_{c e}\right)+r_{e}=\frac{\mu}{\delta \gamma K^{\gamma}} \\
\hat{n}_{c}+\hat{n}_{e}=1
\end{gathered}
$$

